\title{
Local recurrence of gastric cancer after total gastrectomy: an unusual presentation
}

\author{
Bruno Martella ${ }^{1 *}$, Fabrizio Cardin ${ }^{1}$, Renata Lorenzetti ${ }^{1}$, Claudio Terranova ${ }^{2}$, Bruno Amato ${ }^{3}$, Carmelo Militello \\ From XXV National Congress of the Italian Society of Geriatric Surgery \\ Padova, Italy. 10-11 May 2012
}

\begin{abstract}
A 71 years old Italian man had type 3 gastric cancer of the greater curvature. Total gastrectomy with splenectomy and D2 lymph node dissection were performed. After discharge chemotherapy ELF regimen was administred for 6 months. After 16 months from the operation a local recurrence was discovered by CT scan. Surgical en-bloc resection was performed removing pancreatic tail, splenic colic flexure and a portion of left diaphragm. Histological examination confirmed local recurrence of gastric adenocarcinoma infiltrating pancreas, colon and diaphragm with lymph node metastasis.
\end{abstract}

\section{Introduction}

In Western countries gastric cancer still represents a disabling disease: unfortunately late diagnosis is common and loco-regional recurrence rate after surgery alone is high especially in patients with advanced stage disease at the time of diagnosis (gastric wall penetration and lymph node metastasis). Local recurrence may occur also in those patient which had R0 resection: management of these cases is extremely difficult for the involvement of regional structures resulting in poor surgical chances. Therefore multidisciplinary therapeutic approach is necessary to achieve better results. The aim of this report is to refer about an unusual presentation of local relapse in an old patient submitted to a total gastrectomy in which surgical approach permitted a good control of the disease.

\section{Case report}

Male, 71 years old; on July 27, 2004, he was submitted to total gastrectomy with splenectomy and lymph-node dissection (D2) for an ulcerated adenocarcinoma of the greater curvature of the upper third of the stomach. Roux-en-Y stapled esofago-jejunoanastomosis was performed and oral food intake resumed in $7^{\text {th }}$ post-operative day after X-ray control with hydro-soluble contrast. Hospital stay was prolonged by left basal pneumonia

* Correspondence: bruno.martella@sanita.padova.it

${ }^{1}$ Department of Molecular Medicine, University of Padua, Italy

Full list of author information is available at the end of the article associated to pleural effusion; discharge occurred after one month. Histological examination demonstrated an adenocarcinoma (Laurèn intestinal type, Ming infiltrating type) extended to all layers of gastric wall and metastasis to greater curvature lymph-nodes (station 4 of JGCA) [1]; the others stations of JGCA (from 1 to 12, excluded 4) were non metastatic (43 lymph-nodes were examined); it was stage IIIA according to TNM classification (T3 N1 M0) [2]. After discharge chemotherapy was given (Etoposide/ Leucovorin/5-fluorouracil, ELF-regimen) from September 2004 to March 2005. Follow-up was uneventful till December 2005. In this period patient suffered of left hypochondriac pain, mild dyspnoea and anorexia. Esophagojejunoscopy was unremarkable. X-Ray confirmed left basal pleural effusion; blood examination resulted only in CEA increase $(19.3 \mathrm{ug} / \mathrm{L})$. CT scan demonstrated a bulk in splenic area of about $8 \mathrm{~cm}$ in diameter and infiltrating pancreatic tail with adhesions to left diaphragm, left colic flexure and left kidney fascia (Fig. 1). On 7 February 2006, he was submitted to explorative laparotomy that confirmed CT scan report. The bulk was resected en-bloc with pancreatic tail, left colic flexure, a portion of left diaphragm and kidney fascia; bowel continuity was restored by side-to-side stapled anastomosis; diaphragm was directly sutured (Fig. 2). Accurate inspection of abdominal cavity excluded others localizations of the disease. Postoperative period was uneventful as regards surgical problems. Angina attack compared in $9^{\text {th }}$ post-operative day; 


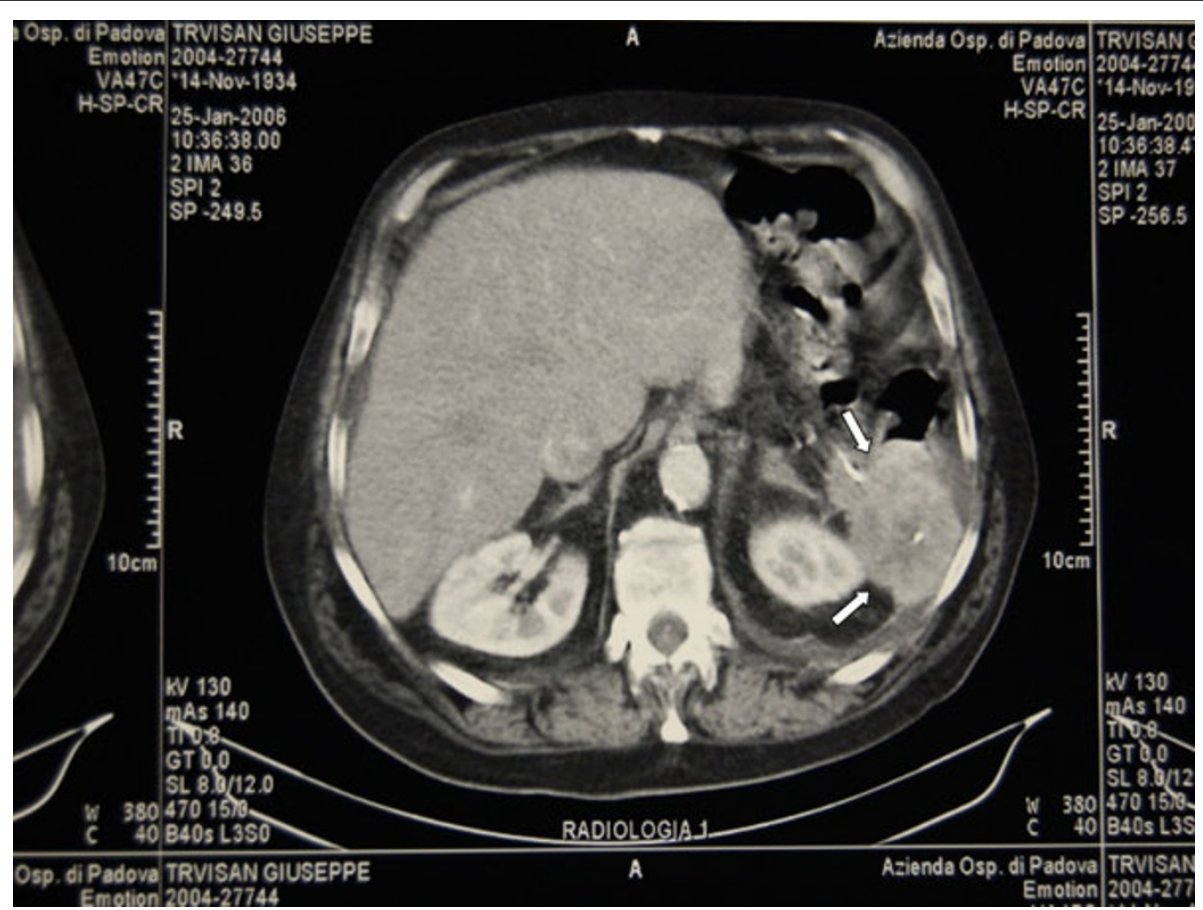

Figure $1 \mathrm{CT}$ scan demonstrating a bulk in splenic area of about $8 \mathrm{~cm}$ in diameter and infiltrating pancreatic tail with adhesions to left diaphragm, left colic flexure and left kidney fascia.

after resolution of this complication patient was discharged. Histological examination resulted in poor differentiated gastric carcinoma infiltrating colic wall and pancreas with metastasis in one of nine peri-colic lymphnodes examinated.

\section{Discussion}

Loco-regional recurrence and distant metastases are common events after surgery for gastric adenocarcinoma.

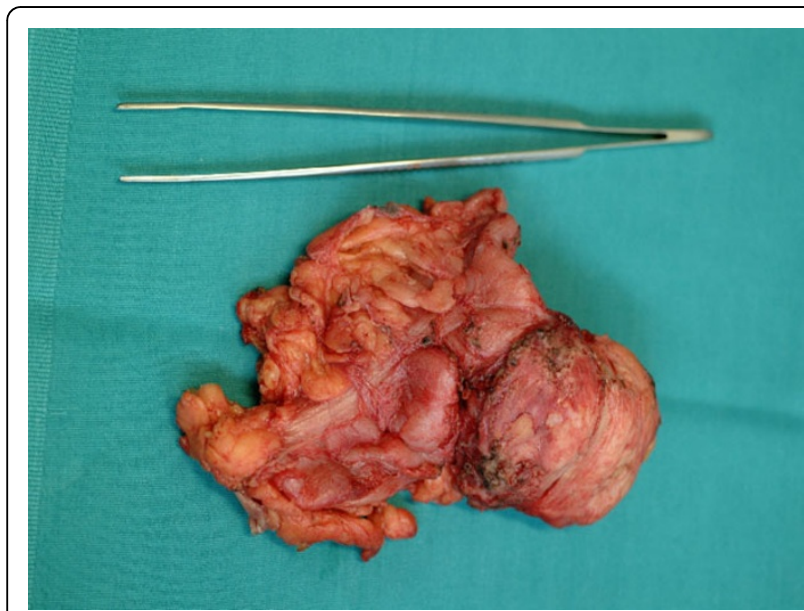

Figure 2 Surgical specimen comprehensive of the bulk resected en-bloc with pancreatic tail, left colic flexure, a portion of left diaphragm and kidney fascia.
Abdominal extraluminal recurrence of gastric cancer is a disarmimg condition because of poor therapeutic chances. Generally it is a matter of peritoneal carcinosis or multiple liver metastasis; in these cases surgery has little opportunities to be useful. Literature reports rare cases of single localization in abdominal cavity that may be resected. Menzel [3] reported a case of infrarenal aortic aneurysm whose detection permitted to discover gastric carcinoma. A similar condition is reported by Shimoyama [4] who diagnosed gastric cancer after nephroureterectomy for hydronephrosis due to ureteral metastasis. Imachi [5] referred about metastatic adenocarcinoma to the uterine cervix. Rare extrabdominal localizations are reported: intramuscular gluteal tumour [6], scalp and forehead [7], testis [8], axillary lymph node [9]. Yoo and Colleagues [8] reported a multivariate analysis of risk factors involved in the recurrence of gastric cancer; in order they are lymph node metastasis, serosal invasion, infiltrative or diffuse type, larger tumour size (4 $\mathrm{cm}$ or greater), undifferentiated tumour and proximally located tumour. Serosal invasion and lymph node metastasis were common risk factors for all recurrence patterns. Buzzoni [10] underlined the role of radical surgery respect more conservative surgery to reduce the rate of loco-regional recurrence: particularly the $\mathrm{pT}$ stage was related to loco-regional recurrence whereas $\mathrm{pN}$ stage had importance on distant metastases. Motoori [11] developed a diagnostic system based on systematic analysis of 
gene expression profiling to predict the recurrence at clinically meaningful level: the prediction accuracy was high especially in patients with small tumours in I and II stage. Marrelli [12] obtained a scoring system with a regression model based on follow-up data to define subgroups of patients at risk for recurrence after radical surgery for gastric cancer. On the other hand, Bennet [13] affirmed that follow-up did not identify no symptomatic recurrence earlier than symptomatic one.

Our case is unusual in its presentation: an isolated bulk involving neighbouring organs suitable for surgical resection. The result after the en-bloc resection is very amazing. Considering the primary surgical specimen we may suppose the modalities of the local relapse: the spleen and local lymph-nodes were radically removed, but in spite of that, local contamination during the first operation remains the most reasonable interpretation. All risk factors suggested by Yoo and Colleagues [8] were present in the initial specimen: serosal invasion and nodal metastases, large tumour size ( $7 \times 5 \mathrm{~cm}$ on the specimen) infiltrative and undifferentiated type and proximally located tumour. We can speculate that chemotherapy has favoured the delay of the clinical presentation of the recurrence. Recently developed new agents such as irinotecan, taxanes and capecitabine, provide more promising results also in metastatic gastric cancer such as new molecular targeting agents [14]. Encouraging perspectives may result from IORT by virtue of its technical properties which permits to exceed conventional doses [15]. We believe that an appropriate association between varies therapeutic option $[16,17]$ (surgery, chemo and radiotherapy - EBRT and/or IORT-) may bring about a change for a better management of recurrent gastric cancer.

\section{Acknowledgements}

This article has been published as part of BMC Surgery Volume 12 Supplement 1, 2012: Selected articles from the XXV National Congress of the Italian Society of Geriatric Surgery. The full contents of the supplement are available online at http://www.biomedcentral.com/bmcsurg/supplements/12/S1.

\section{Author details}

${ }^{1}$ Department of Molecular Medicine, University of Padua, Italy. ${ }^{2}$ Department of Surgical and Gastroenterological Sciences, University of Padua, Italy. ${ }^{3}$ University of Naples Federico II - Department of General Surgery, Italy.

\section{Authors' contributions}

$\mathrm{BM}, \mathrm{CM}$ and $\mathrm{RL}$ have studied the patient and performed the surgical operation. FC performed the endoscopic preoperative study of the patient and contributed to the literature review. CT contributed to the discussion of medico-legal issues and to the writing of the paper. BA and CM gave their contribution to the analysis of the data and contributed to the writing of the paper. All the authors read and approved the final manuscript.

\section{Competing interests}

The authors declare that they have no competing interests.
References

1. Japanese Gastric Cancer Association. Japanese Classification of Gastric Carcinoma - 2nd English Edition. Gastric Cancer 1998, 1:10-24.

2. Sobin $\mathrm{LH}$, Wittekind $\mathrm{CH}$ : International Union Against Cancer (UICC). TNM classification of malignant tumours. New York: John Wiley \& Sons; 51997.

3. Menzel T, Peters K, Hammerschimdt S, Ritter O: Metastatic signet ring cell gastric carcinoma presenting as an infrarenal aortic aneurysm. Gastric Cancer 2005, 8(1):47-49.

4. Shimoyama $Y$, Ohashi M, Hashiguchi N, Ishihara M, Sakata M, Tamura A, et al: Gastric cancer recognized by metastasis to the ureter. Gastric Cancer 2000, 3(2):102-105.

5. Imachi M, Tsukamoto N, Amagase $\mathrm{H}$, Shigematsu T, Amada S, Nakano H: Metastatic adenocarcinoma to the uterine cervix from gastric cancer. Cancer 1993, 71:3472-3477.

6. Kondo S, Onodera H, Kan S, Uchida S, Toguchida J, Imamura M: Intramuscular metastasis from gastric cancer. Gastric Cancer 2002, 5(2):107-111.

7. Lifshitz OH, Berlin JM, Taylor JS, Bergfeld WF: Metastatic gastric adenocarcinoma presenting as an enlarging plaque on the scalp. Cutis 2005, 76(3):194-196.

8. Yoo CH, Noh SH, Shin DW, Choi SH, Min JS: Recurrence following curative resection for gastric carcinoma. Br J Surg 2000, 87:236-242.

9. Kobayashi O, Sugiyama Y, Konishi K, Kanari M, Cho H, Tsuburaya A, et al: Solitary metastasis to teh left axillary lymph node after curative gastrectomy in gastric cancer. Gastric Cancer 2002, 5:173-6.

10. Buzzoni R, Bajetta E, Di Bartolomeo M, Miceli R, Beretta E, Ferrario E, et al: Pathological features as predictors of recurrence after radical resection of gastric cancer. Br J Surg 2006, 93(2):205-209.

11. Mootori M, Takemasa I, Yano M, Saito S, Miyata H, Takiguchi S, et al: Prediction of recurrence in advanced gastric cancer patients after curative resection by gene expression profiling. Int J Cancer 2005, 114(6):963-968.

12. Marrelli D, De Stefano A, De Manzoni G, Morgagni P, Di Leo A, Roviello F: Prediction of recurrence after radical surgery for gastric cancer: a scoring system obtained from a prospective multicenter study. Ann Surg 2005, 241(2):247-255

13. Bennett JJ, Gonen M, D'Angelica M, Jaques DP, Brennan MF, Coit DG: Is detection of asymptomatic recurrence after curative resection associated with improved survival in patients with gastric cancer? J Am Coll Surg 2005, 201(4):503-510.

14. Ohtsu A: Current status and future prospects of chemotherapy for metastatic gastric cancer: a review. Gastric Cancer 2005, 8(2):95-102.

15. Tomio L, Pani G, Agugiaro S, Valentini A, Fellin G, Mussari S: Intraoperative radiotherapy in gastric adenocarcinoma: a long tem analysis on 26 patients. Tumori (supplementi) 2005, 4(6):s43-47.

16. Rispoli C, Rocco N, lannone L, Compagna R, De Magistris L, Braun A, Amato $B$ : Developing guidelines in geriatric surgery: Role of the grade system. BMC Geriatrics 2009, 9(SUPPL. 1), Article n.A99.

17. Guida F, Antonino A, Conte P, Formisano G, Esposito D, Bencivenga M, Aprea G, Amato B, Avallone U, Persico G: Gastric cancer in elderly: Clinicopathological features and surgical treatment. BMC Geriatrics 2009, 9(SUPPL. 1), Article n.A66.

doi:10.1186/1471-2482-12-S1-S28

Cite this article as: Martella et al: Local recurrence of gastric cancer after total gastrectomy: an unusual presentation. BMC Surgery 2012 12(Suppl 1):S28.

Published: 15 November 2012 